\title{
The Health Impact Fund and Its Justification by Appeal to Human Rights ${ }^{1}$
}

\author{
Thomas Pogge
}

\section{Introduction}

One important aspect of globalization is the increasingly dense and influential regime of global rules that govern and shape interactions everywhere. Covering trade, investment, loans, patents, copyrights, trademarks, labor standards, environmental protection, use of seabed resources, production and marketing of weapons, maintenance of public security, and much else, these rules-structuring and enabling, permitting and constraining — have a profound impact on the lives of human beings and on the ecology of our planet. It is therefore important to think carefully, in moral terms, about their design.

With the 1994 adoption of the TRIPS Agreement, the most important rules governing the development and sale of medicines were shifted from the national to the global level. ${ }^{2}$ States implement the rules of the agreement through national legislation and enforcement, but in doing so they are tightly constrained by its terms. In particular, they are required to offer twenty-year patents for a wide range of innovations, including pharmaceutical innovations such as drugs and vaccines.

The introduction of strong pharmaceutical patent protection into the less developed countries has been characterized by many as an unmitigated disaster. My assessment differs in two respects. First, I recognize that patents can play a positive role in meeting the health needs of people in the future, both poor and rich, by incenting pharmaceutical research. The introduction of stronger patent rights in developing countries may be particularly important with respect to tropical diseases. So the disaster is a mitigated one. Second, I believe that it is neither morally necessary nor politically realistic to roll back TRIPS in the domain of pharmaceuticals. The preceding arrangements were by no means perfect; and the structural problems of the status quo can be solved through an institutional complement, the Health Impact Fund (HIF), which is specifically designed to resolve failures in pharmaceutical markets. The crucial moral issue is then not the presence or absence of strong pharmaceutical patent protections, but rather the presence or absence of the Health Impact Fund (or some similar compensating mechanism). 


\section{Assessing the Status Quo through Focused Comparisons with Alternative Options}

Freshly globalized through the TRIPS Agreement, the current regime governing the development and distribution of new medicines-the "status quo" or "SQ"-is often defended through a focused comparison with an alternative possibility. One prominent such defense describes what the world would be like (holding all else fixed) without the practice of rewarding pharmaceutical innovations through patents. In such a world, nearly all the innovative pharmaceutical research currently undertaken by privately owned firms would not occur. The reason is that such research efforts, even if successful, would foreseeably result in economic losses to the innovating company because its competitorsunconstrained by patents-would copy or retro-engineer its invention and would then compete the price of the medicine down close to the long-run marginal cost of production, thereby making it impossible for the innovator to recoup its research and development (R\&D) outlays. Since it is better to have the option of buying commercially developed expensive medicines than to lack this option, a system of patent rewards is clearly better than no rewards at all.

This comparison would sustain a compelling defense of SQ, if there were only these two options available. But this is not so, and the argument is then based on a false dichotomy. It is not much of a defense of how things are to show that they could be even worse. The justifiability of SQ turns not on whether there is any option that is worse, but on whether there is any feasible option that is appreciably better. Exploring this latter question requires creativity and an open mind. One must loosen one's attachment to SQ and then try to develop promising alternatives into their best possible form. Only if we have tried this in a serious and sustained manner, and have failed again and again, can we morally accept SQ with the great burdens it places on poor people.

One commonly proposed alternative to SQ is the "Pre-TRIPS" regime that preceded it: a regime under which states were free to decide separately, each on the basis of its own interests, what rewards, if any, to offer for pharmaceutical innovation. Let us examine this comparison.

\section{Comparing SQ to the Pre-TRIPS Regime}

The main argument for favoring SQ over Pre-TRIPS is that the former may stimulate the development of some medicines that otherwise would have come on the market much later, if at all. When pharmaceutical companies can obtain twenty-year patents in less developed countries and can, thanks to such market exclusivity, sell their medicines there with high mark-ups, they will take such potential earnings into account when deciding about candidate research efforts. To be sure, only a minority of the population of the less developed countries can afford to buy patented medicines. Still, eventually such poor people will also benefit. Once the relevant patents expire, they may have access at generic prices 
to medicines that would not (yet) have been developed without the extension of strong intellectual property rights into the less developed countries.

It is too early for success stories of this kind. Most of the less developed countries were required to institute the TRIPS-mandated product patent rules by January 1, 2005, and certain "least developed" countries still have until January 1, 2016. So the new incentives may well have spawned some of the recent or current research efforts, but no medicine resulting from such efforts has yet become generically available. Patents applied for after January 1, 2005 will not expire until 2025 at the earliest.

In the long run, however, SQ is likely to bring substantial benefits compared to the alternative of no patent protection in developing countries. These will be most obvious in the domain of so-called Type III diseases, defined as ones that occur exclusively or overwhelmingly in poor countries. ${ }^{3}$ These diseases have long been neglected as unprofitable by pharmaceutical research firms. But such firms may well become more interested when the availability of patents in less developed countries allows them to collect high mark-ups there on drugs sold to affluent patients, government agencies, and non-governmental organizations (NGOs).

It may always be difficult to know whether any new medicine for a Type II or Type I disease owes its introduction to TRIPS-expanded intellectual property protections. Still, it is likely that the inclusion of the less developed countrieswhich adds some 500 million affluent people to the 1000 million residents of the high-income countries already in the pharmaceutical market-will accelerate the pace of pharmaceutical innovation in the domains of Type II and Type I diseases as well. Again, access to such TRIPS-incented new medicines will initially be confined to the most affluent quarter of humanity. But eventually, when such medicines come off patent, much larger numbers of poor people will also be able to benefit from their existence.

These important advantages of SQ must be balanced against the advantages of its predecessor. Before the TRIPS Agreement was adopted, most of the poor countries had weak intellectual property protections or none at all, which enabled them to produce or import cheap generic versions of advanced medicines that were patented and thus much more expensive in the affluent countries. Relative to Pre-TRIPS, SQ thus imposes a serious loss on the poorer three-quarters of the human population by pricing out of their reach new medicines that otherwise they could have obtained at generic prices either with their own money or with the help of friends, relatives, NGOs, or governmental or intergovernmental agencies. ${ }^{4}$

Which of the two regimes is morally preferable? It is evident that SQ is preferable for the people of the affluent countries who gain access, on familiar terms, to additional medicines that - without the added market demand for patented medicines from the less developed countries-would have been developed later or not at all.

The comparison is more complex in the case of the affluent minority in these less developed countries. They are better off insofar as they can now buy-albeit initially at high prices-some new medicines that would not be on the market 
without the TRIPS Agreement. They are worse off insofar as they must now pay much more for new medicines that would have been available even without the TRIPS Agreement. It seems plausible that, for this group as well, the gains in terms of health and survival outweigh the financial losses.

The most difficult comparison is that from the standpoint of the poor in less developed countries, who cannot afford to buy new medicines at monopoly prices. This standpoint of the poor ought to be accorded great moral weight, since they constitute about three-quarters of the human population and also have the most at stake. The extension, through the TRIPS Agreement, of strong intellectual property rights into the less-developed countries burdens the poor in those countries by causing to be priced out of their reach all the new medicines that would otherwise have been available to them at generic prices. Yet, this extension of intellectual property rights may possibly also benefit the poor of the future, if the additional incentives it provides lead to the development of important medicines that would otherwise have been developed much later or not at all. To be sure, poor people will not be able to afford such an additional medicine during its initial period under patent. But they may benefit from purchases made on their behalf by aid agencies and governments, and there will come a time when the relevant patents will have expired and these medicines will be available at generic prices. This latter benefit could begin to materialize in 2025 .

It is clear that the magnitude of these burdens and benefits is enormous. Under SQ, millions are unable to afford new medicines during their early years under patent protection and the exclusion of these people from access to advanced medicines will exact a heavy toll of disease and death for the indefinite future. Yet millions of poor people may survive or be healthy in the future thanks to the generic availability of medicines that, but for the additional incentives introduced by the TRIPS Agreement, would have existed only much later if at all.

A clean-cut solution to this dilemma invokes the difference in the time at which the burdens and benefits materialize. Strengthened intellectual property protections in the less developed countries burden the poor immediately by pricing vital medicines out of their reach. Yet, such protections may benefit only future poor people, starting in 2025, when patents on medicines that owe their development to such protections expire. Appealing to this time difference, one might then propose to resolve the dilemma in favor of Pre-TRIPS on the ground that it is morally impermissible to cause severe harms, including death, to poor people now for the sake of protecting even very large numbers of poor people from similarly severe harms later on. Many endorse such a principled stance. Yet, one cannot be satisfied with the outcome it favors in view of all the harm that stimulating new drug development could avert from so many future lives.

It may seem as though compulsory licenses-as envisioned in the TRIPS Agreement and reaffirmed in the 2001 Doha Declaration ${ }^{5}$ - are a practical solution to this dilemma. By issuing a compulsory license, a government can force down the price of a patented invention by compelling the patent holder to license it to another producer for a set percentage (typically below ten percent) of the latter's 
sales revenues. Yet, compulsory licenses cannot fully solve the dilemma because, insofar as governments actually use them to improve access by the poor to patented medicines, compulsory licenses weaken the innovation incentives that were supposed to result from the extension of strong intellectual property rights into the less developed countries. Pharmaceutical companies will understandably discount their new patenting opportunities in developing countries if they are uncertain whether and to what extent they will actually be allowed to profit from such patents.

There is far better solution to the dilemma. The Health Impact Fund, added to SQ, would strengthen pharmaceutical innovation incentives while reliably avoiding high mark-ups that obstruct access by poor patients to new medicines.

\section{How the Health Impact Fund Would Work}

Financed primarily by governments, the Health Impact Fund is a pay-forperformance mechanism that would offer innovators the option-no obligation - to register any new medicine or, under certain conditions, also a traditional medicine or a new use of an existing medicine. By registering a product, the innovator would undertake to make it available, during its first ten years on the market, wherever it is needed at no more than the lowest feasible cost of production and distribution. The innovator would further commit to allowing, at no charge, generic production and distribution of the product after these ten years have ended (if its patents on the product have not yet expired). In exchange the registrant would receive, during that ten-year period, annual reward payments based on its product's global health impact. The reward payments would be part of a large annual pay-out, with each registered product receiving a share equal to its share of the assessed health impact of all HIF-registered products in the relevant year. If the HIF were found to work well, its annual reward pools could be scaled up to attract an increasing share of new medicines.

The HIF would foster the development of new high-impact medicines-also against diseases concentrated among the poor, such as tuberculosis, malaria, and other tropical diseases, which are now neglected because innovators cannot recover their $R \& D$ costs from sales to the poor. The option of an alternative reward based on global health impact would transform heretofore neglected diseases into some of the most lucrative pharmaceutical R\&D opportunities. The HIF would also promote access to new medicines by limiting the price of any registered product to the lowest feasible cost of production and distribution. In addition, the HIF would motivate registrants to ensure that their products are widely available, perhaps at even lower prices, and that they are competently prescribed and optimally used. Registrants would be rewarded not for selling their products, but for making them effective toward improving global health.

If some pharmaceutical $R \& D$ were financed through tax-funded HIF rewards, much of the cost would be borne by affluent populations and people-just like today. But there are important differences. First, innovators make no profit from 
the sale of their medicine as such-they profit only insofar as this medicine is actually made effective toward improving patient health. Thanks to this new incentive, patients are more likely to receive medicines that will actually improve their condition. Second, in order to profit from serving affluent patients, innovators do not need to exclude poor patients. On the contrary, they profit equally from serving poor patients, too, at the same low price. Health gains achieved for any patients - rich or poor - contribute equally toward the innovator's bottom line.

The HIF will provide optimal incentives only if potential registrants are assured that the rewards will actually be there in the decade following market approval. Core funding of the HIF is therefore best guaranteed by a broad partnership of countries. If governments representing one-third of global income agreed to contribute just 0.03 percent of their gross national incomes ( $\$ 3$ of every $\$ 10,000)$, the HIF could get started with $\$ 6$ billion annually. This is a reasonable minimum because the high cost of developing new medicines requires large rewards and also because the health impact assessment costs should not absorb more than about ten percent of the HIF budget.

The HIF can be seen as an ongoing competition among innovators that ranges over all countries and all diseases, with firms earning more money if their product has a larger impact on health. Health impact can be measured in terms of the number of quality-adjusted life years (QALYs) saved worldwide. The QALY metric is already extensively used by private and state insurers in determining prices for new drugs, so employing it in calculating HIF rewards is not a big leap. Taking as a benchmark the pharmaceutical arsenal before a registered medicine was introduced, the HIF would estimate to what extent this medicine has added to the length and quality of human lives. This estimate would be based on data from clinical trials, including pragmatic trials in real-life settings, on tracking randomly selected medicines (identifiable by serial numbers) to their end users, and on statistical analysis of sales data as correlated with data about the global burden of disease. ${ }^{6}$ These estimates would necessarily be rough, at least in the early years. But so long as any errors are random, or at least not exploitable by registrants, HIF incentives would be only minimally disturbed.

With the HIF so designed, innovators would choose to register products that can reduce the global burden of disease most cost-effectively. Products with the largest health impact would make the most money-creating exactly the right incentives for innovation. And because the HIF would be an optional system, the rate of reward is certain to be reasonable. If rewards were too high, new registrants would enter and reduce the uniform reward rate (dollars per QALY). If profits were too low, the reward rate would naturally increase as firms would choose, for more of their new products, to forego HIF registration in favor of exploiting their patent-protected pricing powers. Competition would ensure that registered products are rewarded at a rate that is profitable for innovators and maximizes the effect of the HIF.

To be certain that the HIF is cost-effective relative to other public health expenditures, one can stipulate a maximum reward rate; if one year's funds are not 
fully used, the remainder can be rolled over into future years. To reassure potential innovators, one can also add some protection against unreasonably low rewards. ${ }^{7}$

\section{Comparing SQ to SQ + HIF}

The world's governments can now, while retaining the TRIPS Agreement and its benefits, take an important step toward freeing the poorer three-quarters of humanity from imprisonment in a cycle of mutually reinforcing poverty and ill health, while also benefiting the fourth quarter-those who are relatively wealthy. No government will want to create the HIF single-handedly. But it can easily be created by a group of states even if others choose not to participate. Many of the richer states could afford to create it on their own. And every country, no matter how small or how poor, can publicly declare its commitment to start or join a partnership of countries ready to underwrite the HIF.

This is then the central moral question we face: Given the available option of adding the HIF to the existing global patent regime, is it morally permissible to continue SQ? Is it morally permissible for any state to reject the HIF in favor of $\mathrm{SQ}$ ?

Answering this question requires discussing what difference the creation of the HIF would make and then assessing this difference in moral terms. I discharge the former task in the present section and the latter in the next.

The most important consequences of creating the HIF can be brought under three headings: Innovation, Price, and Last Mile.

\subsection{Innovation}

The HIF would mitigate the long-standing problem of incenting the development of new medicines that would have large health impacts but small profits under SQ-because of impoverished markets, for instance, or because of inadequate protection from competition (as in the case of new uses). With the HIF in place, all diseases that substantially aggravate the global burden of disease would come to be among the more lucrative pharmaceutical research opportunities. Without losing any of their present opportunities to cater to the health needs and fads of the affluent, pharmaceutical companies would have additional opportunities to develop new medicines against heretofore neglected diseases, and they would be incented to do so with an eye to prioritizing the diseases they can fight most cost-effectively. The notion of cost-effectiveness relevant here relates a familiar notion of cost to a rather unfamiliar notion of benefit. Costs comprise the large fixed costs of bringing a new medicine to market (research, patenting, testing, and obtaining regulatory approval) plus the variable costs of production, distribution, and marketing. Benefit is the assessed global health impact attributable to the new medicine. Given similar costs across the various plausible target diseases, firms will concentrate on researching the diseases against which the largest health impact can be achieved. These will include HIV/AIDS, tuberculosis, 
malaria, and various other tropical diseases — such as dengue fever, leprosy, trypanosomiasis (sleeping sickness and Chagas disease), onchocerciasis (river blindness), leishmaniasis, Buruli ulcer, lymphatic filariasis, and schistosomiasis (bilharzia) - in regard to which the present arsenal of pharmaceutical interventions is woefully inadequate.

\subsection{Price}

The HIF-registered medicines will be available worldwide at very low prices, usually even below prices currently charged for comparable generic medicines. ${ }^{8}$ HIF registrants will be obliged by contract to sell their products everywhere at no more than the lowest feasible variable $\operatorname{cost}^{9}$ and will, in the case of the most therapeutically effective products, have an incentive to choose even lower prices. ${ }^{10}$ Some such cheap HIF-registered medicines would not have been developed but for the HIF. But there will be other cheap registered medicines that could have been profitably developed even without the HIF. In these latter cases, the innovating firm could choose high prices to exploit the market exclusivity to which it is entitled during the life of its relevant patents. The firm nonetheless chooses to register its product with the HIF because it expects to make more money by foregoing high prices in favor of health impact rewards. In such cases, the HIF does not bring the medicine into existence, but still makes a huge difference to its price during its years under patent. Products priced by a profit-maximizing monopolist are always marked up to the point where some cannot afford them. When economic inequalities are vast (as they are today on the global plane), the profit-maximizing price may exclude a large majority of potential buyers. ${ }^{11}$ When the products are important new medicines, the aggregate harm suffered by this excluded majority can be staggering. Because registration would be especially attractive for such high-impact drugs, the HIF would greatly mitigate this harm resulting from the current exclusion of a majority of humankind from medicines that can be manufactured very cheaply.

\subsection{Last Mile}

Poor people's access to vital medicines is currently obstructed by various obstacles other than price, such as lack of local availability of a medicine, lack of refrigerator or electricity, lack of available knowledge and information about diseases and their remedies, and gross negligence, incompetence and corruption in the health systems of many poor countries. Many governments of such countries have shown themselves unable or unwilling to address these obstacles. Inability is often a matter of lack of resources as when a poor country's government lacks the funds to train and retain local doctors and nurses. Unwillingness is typically due to a lack of democratic accountability which allows rulers to stay in power and prosper even while the poorer segments of their country's population are decimated by malnutrition and disease. HIF registrants are much better 
positioned than the very poor to respond to such government failures. Incented to make their registered medicine competently available to as many poor patients as they can cost-effectively reach, such registrants would-presumably in collaboration with one another and with locally operating international agencies and NGOs - provide knowledge, information, expertise, training, and funds to help maintain basic health infrastructure wherever they can profitably do so. Such registrants may also bring the pressure of publicity to bear on governments that obstruct health improvements for their poor compatriots. To be sure, these are tasks that other governments, media, NGOs, and private citizens should also tackle. But more effort than presently expended is clearly needed, and profitoriented companies can make an important contribution.

\subsection{May Those Who Expect No Gains from the HIF Insist on SQ?}

Benefits in terms of innovation, price, and the "last mile" accrue not only to poor people in less developed countries. We all benefit when pharmaceutical firms organize themselves for optimal health impact: when their innovations target the most burdensome diseases and when they market their products for optimum disease reduction and not merely for sales. And low prices for advanced medicines will have a large impact on poor people in the United States no less than in Haiti, because high prices deter the poor everywhere from purchasing medicine. Even in countries with publicly financed universal health insurance coverage, high prices may lead to certain products being excluded from formularies and may thereby make these products inaccessible even to patients who have (public or private) insurance that covers medicines.

The HIF would greatly reduce the cost of medicines even for the affluent, who currently pay-directly or else through taxes or insurance premiums-the lion's share of all costs for pharmaceutical research. Taking account of these savings, the net cost of the HIF even to the affluent would at most be a fraction of the nominal cost they would bear through the tax system.

Considering together how the addition of the HIF to SQ would affect the various groups, it may seem evident that the benefits outweigh the cost. But some of the more affluent populations may not be moved by such considerations. They might say: "Let us take for granted that the HIF is feasible and would work as intended. It is then surely morally better for there to be a well-funded HIF rather than none, and morally better for our countries to offer to participate in such a Fund rather than to decline. But it does not follow from this that our countries are morally required to support the HIF-no more than it follows from the fact that it would be morally better if a rich woman gave half her assets to charity that she has a moral obligation to do so. It is morally permissible for each government to make this decision on the basis of the interests of its own citizens. If the costs of the HIF to us are larger than its benefits to us, then our governments may permissibly decline to participate even if this decision leaves large disease burdens in other countries unalleviated. And we suspect that, indeed, the HIF's benefits for us will 
be small if many of the additional medicines the HIF would induce are for tropical diseases from which we have little to fear. We will gain, to be sure, from low prices of some medicines that would otherwise be sold with high mark-ups. But these savings may not be large enough to justify the contribution we would be making to the HIF."

This nationalist standpoint is widespread. It can be addressed in two ways. One way involves arguing that creating the HIF would not worsen the situation, relative to SQ, of people living in the affluent countries-that the additional taxes they would pay through the tax system would be fully compensated by the HIF's advantages for them. These advantages include the availability of cheap HIFregistered medicines, which would also bring indirect benefits through savings on insurance premiums, on national health system outlays, and on foreign humanitarian and development assistance. Residents of affluent countries would also benefit from pharmaceutical companies refocusing their innovation and marketing priorities from sales toward health impact. HIF-stimulated research projects would moreover augment our knowledge about the most dangerous diseases and their mutations, would reduce their incidence, and would thereby make everyone safer. In addition, people in affluent countries would benefit from HIF-stimulated growth of their national pharmaceutical industry as well as from the globally improved productivity that better health worldwide would bring in its wake. This global productivity gain would be all the greater insofar as the HIF would substantially raise the efficiency (QALY per dollar) of the entire pharmaceutical system. ${ }^{12}$

In this essay, the nationalist standpoint is addressed in a different way: by challenging its legitimacy in this case. Let us assume for the sake of the argument that the HIF would, relative to SQ, cost some group of affluent people more than it would benefit them. I argue that these people would still not be entitled to insist on SQ because SQ imposes morally unacceptable burdens on poor people. These burdens are shown to be reasonably avoidable by the availability of SQ + HIF as a feasible alternative option; and the continuation of SQ is then morally impermissible.

This does not mean that the affluent, or anyone, are morally required to support the HIF, for there may be other ways of averting the unjust burdens SQ imposes. ${ }^{13}$ But it is not enough merely to point to such another alternative to SQ and then to do nothing further. The other alternative must be elaborated in detail and then be politically implemented. And it is not easy to specify an alternative to SQ that is superior to SQ + HIF. Because the HIF operates globally, it dilutes the cost for each country without diminishing the benefits it receives. Covering all diseases, all medicines, all regions, and all patients, the HIF offers innovating firms a large space in which they can, impelled by competitive pressures, optimize cost/benefit; the HIF thus greatly enhances both innovation and access. Operating into the indefinite future, the HIF moreover takes full advantage of long-term incentive effects. If the HIF is indeed the most cost-effective solution, then the affluent have prudential reasons to endorse the HIF as the (for themselves) most advantageous permissible regime. 
If SQ is impermissible, then modifying it, even if this were to worsen the position of some affluent people, is not charity-no more than it would be charity for a slaveholder to release his slaves or for the rich woman to give up assets that do not belong to her. The woman's insistence that she is entitled to retain possession of her wealth can be challenged by showing that this wealth is not legitimately hers. Analogously, any insistence by the affluent that they are entitled to maintain SQ can be challenged by showing that SQ is grievously unjust. This challenge can be based on an appeal to human rights.

\section{Human Rights as a Globally Sharable Minimal Standard of Institutional Assessment}

The moral argument for creating the HIF would be greatly strengthened if it could be shown that SQ is unjust. But showing this would seem to presuppose a widely shared conception of global justice. There is as yet no such conception widely endorsed across regions and cultures. I seek to overcome this lack through a two-stage argument.

The first stage (the present section and the next) builds on the realization that, while an international consensus on global justice is lacking, it is also not the case that there is no agreement whatsoever. There is a widespread and enduring consensus on one basic element of a conception of justice, namely on the high moral priority of certain fundamental human rights. To be sure, human rights constitute very minimal requirements, and most would reject the view that anything that does not violate human rights is therefore permissible. By adopting a human rights standard, I do not endorse this view but merely commit myself to the converse: anything that does violate human rights is therefore impermissible.

The second stage of the argument (the last three sections of this essay) shows that the answer delivered by a human rights assessment cannot be overturned by other morally relevant considerations. I can display some work on this second stage here, in an exemplary way. But I cannot, of course, work through all the moral considerations that could be claimed to be alive in some country or culture in order to show that none of them generates reasons that would undermine or override my human-rights argument for creating the HIF.

Human rights have come to be understood as entailing counterpart duties to respect, protect, and fulfill. ${ }^{14}$ Presupposing this understanding, it would not be difficult to show that adding the HIF to SQ would be a great advance in terms of protecting and fulfilling human rights-especially social and economic human rights as formulated, for example, in the 1966 International Covenant on Social, Economic and Cultural Rights which expands upon Article 25 of the 1948 Universal Declaration of Human Rights:

Everyone has the right to a standard of living adequate for the health and well-being of himself and of his family, including food, clothing, housing and medical care. ${ }^{15}$ 
Many people in the affluent countries claim, however, that they and their countries do not have such "positive" duties to protect and fulfill. These people recognize human rights only in the narrow sense where the only duties these rights entail are duties to respect, that is, duties not actively to violate human rights. I do not endorse this view. But in order to present as broadly based an argument as possible, I work with this narrow understanding of human rights throughout.

So understood, human rights constrain how agents-principally governments, but also corporations, military units, rebel groups, and other organized collective agents - may treat human beings. The human-rights violating treatment in question may involve direct action: as when a government terrorizes opposition candidates and voters, or tortures prisoners. In other cases, human-rights violating treatment is built into social rules, as when discriminatory burdens are imposed by law on certain minorities, or when a government policy systematically deprives some group of its livelihood. The latter kind of case is relevant to our topic: to the choice between alternative rules governing the development and distribution of new medicines. In such cases, it is in the first instance the rules or policies that violate human rights. But in the final analysis these violations are committed by those who formulate, interpret, and enforce these rules and policies and by those on whose behalf the former are acting.

There is another dimension in which human rights can be given a wider or narrower understanding. The demand that social rules must be human-rights compliant is often interpreted to entail that a state realizes a particular human right only if it explicitly incorporates this right into its laws or constitution. So interpreted, the demand has been rejected by many, most prominently by appeal to "Asian values." 16 This rejection involves the thought that human rights promote individualism or even egoism, lead persons to view themselves as Westerners-as atomized, autonomous, secular, and self-interested individuals ready to insist on their rights no matter what the cost may be to others or to society at large.

Once again, I do not endorse this rejection. Yet, in order to present as broadly based an argument as possible, I appeal here to human rights in a narrower, more widely sharable sense. This sense can be explicated as follows: There are various basic goods that are essential to a minimally worthwhile human life. All human beings ought to have secure access to these goods. Insofar as is reasonably possible, social rules should then be so designed that the human beings subjected to them have secure access to these essentials. This is what human rights require. The assertion that there is a human right to a minimally adequate food supply entails then that, insofar as reasonably possible, social rules must be formulated so that all human beings have secure access to a minimally adequate food supply. This assertion does not entail that human beings must have a legal right to a minimally adequate food supply. If a state is so organized that its citizens have secure access to food even without a legal right thereto, then this state is fully compliant with the human right as I understand it.

This understanding of human rights is not subject to the usual critique based on Asian values. Rather, it accommodates the central point of this critique: human 
rights leave each state free to decide how to achieve secure access to their objects. Some societies may choose to do this through legal rights and legal institutions; others may do this through a communal ethos of virtue and solidarity. So long as people really have secure access to the objects of their human rights, both models, and others as well, are fully human-rights compliant in the narrow sense I invoke.

\section{The Applicability of Human Rights to Supranational Regimes}

The development and sale of medicines worldwide is governed by certain national and international rules, centrally including the TRIPS Agreement. Do these rules as they currently operate in the real world (SQ) violate human rights?

Some may want to reject this question as ill-posed. While national laws can violate human rights, they hold, international rules and treaties cannot in principle do so. But this is not a plausible objection. Imagine a state that has made it legally permissible to assault those who join a labor union. Such a law is a clear-cut violation of the human right to life, liberty and security of person. This human right violation does not disappear when the relevant state concludes an international agreement that commits it to the offensive legislation. On the contrary, the fact that several states jointly commit themselves to the offensive legal permission can only heighten their responsibility. With the agreement, each state remains fully responsible for the human-rights-violating character of its own national legislation and assumes in addition some responsibility for the contractually mandated human-rights-violating laws that other treaty members are imposing within their territories. States that bind one another to the imposition of humanrights-violating rules become accomplices in one another's human rights violations. Human rights constrain then the design of international rules and treaties no less than that of national legislation.

This conclusion is firmly endorsed in the Universal Declaration of Human Rights:

Everyone is entitled to a social and international order in which the rights and freedoms set forth in this Declaration can be fully realized. ${ }^{17}$

Again, I use the doubly narrow understanding of human rights in interpreting this Article. It then requires that any national and international order must be shaped so that it does not deprive human beings subjected to it of secure access to the objects of their human rights. In a world of sovereign states, it may not be possible to design international institutional arrangements that effectively guarantee secure access. For this reason, it makes sense to require merely that the international order must be such that secure access can be fully realized. The international order must not obstruct the realization of human rights. It must not, for instance, undermine either the capacity or the willingness of national governments fully to realize human rights. A design of the international order fails 
to be human-rights compliant insofar as it foreseeably gives rise to an avoidably large number of governments that lack either the means or the motivation to realize human rights.

Today, most human beings lack secure access to the objects of their human rights. In particular, many of them lack secure access to the medicines they need. Often, these medicines are known and available, but nonetheless not accessible to the poor on account of their high prices. There are generic producers willing and able to manufacture these medicines and to sell them at much lower prices. But these firms are legally barred from doing this by patents that governments are issuing in accordance with their commitment under the TRIPS Agreement. This agreement blocks mutually advantageous sales of lifesaving medicines at low prices. By blocking such sales, it causes the deaths of many poor people and deprives many more of a standard of living that is adequate for their health. (The very high mark-ups on patented medicines may render inadequate an income that would be adequate if the needed medicine were available at a lower price.) SQ is violating the human rights of poor people worldwide by undermining their secure access to health and survival.

This conclusion can be disputed by appeal to the benefits of SQ. Here the most significant benefit, which can also be cast in human rights terms, is the future availability of important medicines that would not have existed if strong patent protections had not been extended into the less developed countries. This benefit can be appealed to by pharmaceutical companies, which can say: "If we did not fully exploit our patent privileges, we would not have the money to undertake many of the research projects we are now engaged in. And there would then be fewer important medicines coming off patent in the future, fewer good medicines that will protect poor people in the future. Some poor people suffer and die now because of the high prices we charge under patent protection. But more poor people will be saved in the future, after expiration of the patents that enabled us to finance the innovation. And the cost is necessary for realizing the greater gain: we simply cannot develop new medicines that future poor people will be able to obtain at generic prices unless we keep raising money by charging high prices for medicines still under patent protection."

While pharmaceutical companies can plausibly make this argument, governments defending SQ can not. To be sure, these governments can point to the benefit of additional new medicines that, thanks to TRIPS, may become generically available starting in 2025 . And they can claim that this benefit will outweigh the burden of high prices that is excluding the poor from advanced medicines in their first ten years or so. But such governments cannot say that they had to impose this burden in order to secure that benefit. The SQ + HIF option makes it possible to achieve for future people access to important additional medicines at low generic prices without preventing poor people from buying these medicines cheaply in their early years on the market. It is morally impermissible to violate the human rights to life and health of millions of people in order to secure a benefit that can also be secured without inflicting such harms. 
This concludes the human rights argument. Appealing to human rights that governments themselves have repeatedly recognized as binding constraints, this argument shows that, if a HIF-like complement to SQ is feasible, then adding it to $\mathrm{SQ}$ is morally required for the sake of realizing the human rights of the global poor. Under the existing international order, these human rights are not realized as the poorer majority of the world's people lack secure access to a standard of living adequate for their health and well-being. One factor preventing their secure access is the suppression of the trade in generic versions of important new medicines. The possibility of adding the HIF to this order shows that much of the present human rights deficit is avoidable. Maintaining SQ without the HIF constitutes a massive violation of the human rights of the global poor. So long as there will be poor people in this world - whether in poor or rich countries - who are unable to obtain medicines at patent-protected high prices, SQ will gravely harm, and kill, many of them. Governments know this; and if they continue to impose and enforce SQ nonetheless, they are violating the human rights of these innocent people.

The next three sections consider and refute three popular replies aiming to defeat the human rights argument.

\section{First Reply: Appealing to the Poor Being Doomed Anyway}

Representatives of pharmaceutical companies often argue that high prices are not the "real reason" why so many poor people are excluded from advanced medicines. Most of those who cannot gain access to patented medicines would still lack access even if these medicines were not patented in their country. This is so because the health systems in many poor countries are in very bad condition, making it highly unlikely that the right medicine would be prescribed, dispensed, and consumed, and also because many of these patients are so poor that they would find it difficult or impossible to pay for the needed medicine even at marginal cost. That this is so is made evident by the fact that poor people often lack access even to the cheap off-patent medicines they need. Introducing into the less developed countries high pharmaceutical prices protected by much strengthened patent protections is therefore doing little harm. It is not substantially worsening the situation of poor people who are in any case doomed to suffer, without health care, from many diseases.

These claims are true for some, but not all, patients. The much lower prices typical of generic medicines would expand access substantially, most obviously among poorer people in the more affluent countries. And even in the poorest countries, low prices of high-impact medicines would greatly magnify the capacities of government health systems, of international organizations such as UNICEF, of NGOs, and of various initiatives such as PEPFAR, GAVI, and GFATM. ${ }^{18}$ The resources of all these agents and agencies-woefully insufficient to meet the huge health needs of the global poor-would stretch much farther if they could buy medicines generically rather than at patent-protected high prices. 
Moreover, the reply is morally troubling. Its central thought is that a barrier that prevents people from protecting themselves is morally acceptable-that is, may be interposed and need not be removed-so long as there is another barrier that is also preventing them. The problem with this idea is that it symmetrically justifies - and thereby helps perpetuate-both barriers: "if each of two barriers is sufficient to prevent a person from saving her life, then there is nothing wrong with either barrier." Or, for the sequential case here at issue: "there is nothing wrong with erecting a further barrier excluding the poor from access to vital new medicines when this barrier adds little to the harm done by already existing barriers." This is a very strange morality indeed. According to it, a barrier that is objectionable on account of the harm it inflicts becomes unobjectionable in the presence of a second barrier that has the same effect.

An obvious alternative to this bizarre idea is that no such barrier is acceptable, and that governments ought to remove all of them, or at least those that are their responsibility. The governments of affluent countries, in particular, should not impose asymmetrical global trading arrangements that prevent many poor populations from participating in global economic growth and thereby reaching minimally adequate levels of income and wealth. They should not pressure or induce the governments of poor countries to collect monopoly rents for their pharmaceutical companies from poor populations chafing under heavy disease burdens. And they should allow poor countries to build effective health systems rather than raid these countries for doctors and nurses who were trained there at great cost to the local population that urgently needs their services. The HIF is designed to meet these obligations by helping to remove the institutional barriers that stand between poor people and the medical care they need. The HIF makes new medicines available to everyone at variable cost and it also provides incentives to the registrants of such medicines to promote their effective use.

To sum up, the first reply to the human rights argument fails on three counts. First, it is factually incorrect that high prices for patented medicines make no difference to the health situation of patients worldwide. Second, it is not morally permissible gravely to harm other people so long as they would suffer a similar harm in any case. A barrier that prevents people from obtaining lifesaving medicine from willing generic suppliers is not acceptable merely because there is another barrier that does the same job. Third, other last-mile barriers, which all too often exclude poor people even from cheap generic medicines, are likewise avoidable effects of institutional arrangements and, like the price barrier, would be greatly reduced by the HIF.

\section{Second Reply: Appealing to "Volenti Non Fit Iniuria"}

Moral criticisms of the current global pharmaceutical patent regime (SQ), and of other international rules deemed unfavorable to the poor, are often rejected as inconsistent with a proper recognition of the sovereignty of states. All states governed by the requirements of TRIPS have freely signed up to these require- 
ments, with no HIF on the horizon at that time; and any complaint on their behalf against SQ is thereby preempted. As that venerable Latin precept has it: volenti not fit iniuria-no injustice is being done to those who consent.

A customary retort to the volenti defense points to the highly unequal bargaining power and expertise of the national delegations that negotiated the WTO Treaty. Most countries were excluded from the drafting of the treaty (the so-called Green Room negotiations) and many of them lacked the expertise to evaluate the extremely long and complex treaty text they were then offered: "Poor countries are also hobbled by a lack of know-how. Many had little understanding of what they signed up to in the Uruguay Round. That ignorance is now costing them dear." 19 With regard to many less developed (and even a number of affluent) countries, there are then serious questions about whether the consent they gave was free and well-informed.

Even if a state's consent to SQ was well-informed and freely given, it is still problematic to appeal to such consent in order to rebut the charge that SQ violates human rights. This is so, because human rights are the rights of individual human beings, and SQ received the consent of governments. Not all governments are democratically elected or responsive to the interests of the people they rule. Among the signatories of the TRIPS Agreement were, for instance, the Nigerian government headed by Sani Abacha, the SLORC military junta of Burma/ Myanmar, the Indonesian government controlled by Suharto, Zimbabwe's government under Mugabe, and the government of Congo/Zaire headed by Mobuto Sese Seko. As this list illustrates, many of the consenting governments ruled by force and did not represent, or show much concern for, the will or interests of the people they ruled. Insofar as they gave free and informed consent, it was driven by their own personal interests and therefore not indicative of the consent of their compatriots. It makes no sense then to contend that an international regime cannot possibly be violating the human rights of the citizens of Nigeria because Sani Abacha once consented to this regime. Those who manage to acquire and hold power in a country, by whatever means, do not thereby become entitled to waive the human rights of the people they are subjecting to their rule.

A further problem is that the appeal to consent is supposed to justify imposition of the regime upon people who were children or unborn at the time the consent was given. Thus, even if every adult citizen of every participating country had given free and informed consent to the TRIPS Agreement at its adoption in 1994, these consenters could not thereby have waived the human rights of their children. Nor could they have waived the human rights of all the people born in these countries since that time-today's children, who are bearing a disproportional share of the global burden of disease (about half the avoidable deaths each year are of children under age five).

Finally, on the predominant understanding of human rights, these rights are inalienable. This means that they cannot be waived or relinquished at all. One main rationale for such inalienability is the need to protect people against losing their human rights protection through fraud, blackmail, manipulation, threats, or 
inducements. ${ }^{20}$ If human rights are indeed inalienable, then the appeal to consent cannot undermine in even a single case the charge that SQ violates human rights.

I have raised four mutually independent objections to the idea that an appeal to consent can shield SQ from the challenge that it violates the human rights of those whom it deprives of access to vital medicines at competitive prices. If even one of these objections is valid, then the appeal to consent fails so to shield the regime.

\section{Third Reply: The Libertarian Appeal to Property Rights}

Another way of rejecting the human rights argument is rooted in the libertarian moral tradition which goes back to John Locke and is characterized by the endorsement of strong rights to freedom and property. This tradition supports a powerful reply to the human rights argument-a reply that resonates in current debates about the TRIPS Agreement and finds much sympathy especially in Anglophone countries. This reply endorses and invokes the narrow understanding of human rights according to which the only duties these rights entail are duties to respect human rights, that is, duties not actively to violate such rights. It then points out that property owners who refuse to share their wealth-including their medicines-with poor people are not human rights violators, even when their refusal foreseeably causes human rights to go unfulfilled. Such property owners are not actively harming the poor, but merely failing to help them.

The reply then adds as a further claim that human rights to life and health do not impose duties to develop, or to fund the development of, new medicines that others need for health or survival. Affluent people are entitled to pay for the development only of medicines they need themselves while declining to pay for the development of medicines needed by the poor. When affluent people do this, they are merely failing to fulfill human rights, not violating them.

The following two subsections unpack and refute these two claims of the libertarian rejoinder.

\subsection{Denying the Poor Access to Generic Medicines}

Property owners are entitled not to share what they own even with poor people whose human rights will remain unfulfilled as a result. To be meaningful, this entitlement must include the entitlement actively to defend their property against those who would take it (even for the sake of fulfilling human rights). Owners are entitled to protect their property against theft, with walls, doors, and locks-and even with force if need be. Such protection of property must often be active, as when an owner physically prevents poor people from stealing his food. Still, such an owner does not violate human rights, because he is merely blocking interference from others, not interfering with them. He is merely protecting his right not to help. 
Owners entitled to protect their property are also entitled to authorize others to do so-for example, the police. And the police are then entitled actively to prevent attempts to steal even when such attempts aim to fulfill human rights. In this way, the creation and enforcement of legal property rights can be defended: such a regime for protecting property should not count as violating human rights even if, as a result of its suppression of theft, human rights remain unfulfilled.

The last step in the rejection of the human rights argument posits that what holds for physical property also holds for intellectual property: a system of rules that defends intellectual property should not count as violating human rights even if, as a result of the suppression of theft, human rights remain unfulfilled. SQ is precisely such a system. It suppresses the trade in generic versions of new medicines and may thereby cause the deaths of poor patients who cannot gain access to the medicine they need because of its patent-protected high price. Even if this suppression of theft of intellectual property is sometimes active, it constitutes no violation of human rights, but merely a failure to fulfill human rights by redistributing the wealth of shareholders in pharmaceutical companies or by leaving their property unprotected.

The TRIPS Agreement gave pharmaceutical innovators legal rights they did not have before: rights to strong twenty-year patent protection in the less developed WTO member countries. The creation of these new property rights cannot be defended by appeal to these same legal property rights. Such a defense would be arguing in a circle. The defense can succeed only if it justifies the creation and enforcement of legal property rights by appeal to independently existing moral or natural property rights. It is only because innovators have a moral right to the fruits of their creative efforts that it is permissible to use legal rights and law enforcement to defend their possession of these fruits even when such defense leads to misery and death of innocent people.

To see how the libertarian argument presupposes such moral or natural property rights, imagine a government passing and enforcing a new law that makes the president's son the owner of all unowned water. As people run out of water, its price shoots up, and soon there is only one person from whom water can legally be bought or received. The rich buy what they need from this man, and the poor suffer and die. Clearly, the law in this story is grossly unjust. Libertarian thinkers would join in its rejection because that law cannot be justified as protecting the man's legitimate property rights. When the law came into being, this man had no special claim to the water not owned by others and hence no claim to have others be excluded from it.

A contrasting scenario, and one that libertarians might well approve, is one where the government passes and enforces a law that recognizes those who plant and harvest food as the owners of this food, so that one can acquire food grown by others only by buying (or receiving) it from them. People who run out of food buy more from others, if they can. But if they lack the money to do so, they suffer and die. In this case the law arguably does not violate human rights because it merely defends antecedently legitimate property rights. Perhaps human rights would be 
better fulfilled if those without money and food were legally free to help themselves to food grown by others. But the suppression of such acquisitions counts as merely a failure to fulfill human rights, not as an active violation — on the libertarian assumption that the growers of food have a moral claim to this food, and a claim to withhold it from others: claims that the law merely recognizes but does not create.

The philosopher Robert Nozick has explicitly extended this line of thought to justify excluding poor people from medicines. He imagines a medical researcher who invents new highly effective medicines whose composition no one else knows. Nozick affirms that this researcher is entitled to withhold the medicine from others, even if their lives are at stake. To explain this entitlement, he writes: "A medical researcher ... does not worsen the situation of others by depriving them of whatever he has appropriated. The others easily can possess the same materials he appropriated; the researcher's appropriation or purchase of chemicals didn't make those chemicals scarce in a way so as to violate the Lockean proviso." 21 The Lockean proviso here alludes to a principle Nozick adapts from John Locke. This principle allows people to acquire natural resources-by appropriation or through gift or exchange-provided they leave "enough and as good" for others. Each person's acquisition of raw materials must be consistent with a like acquisition by others. Because the production of drugs tends to require only small amounts of ingredients, it easily fulfils this condition in nearly all cases.

To be sure, by keeping all the medicine to himself, Nozick's researcher is not leaving enough and as good medicine for them. But he is not required to do so, because this medicine is his own product and would not exist but for his labor. By producing this medicine just for himself, the researcher is not taking anything away from others. He is merely failing to let them participate in his invention by sharing with them either his medicine or his knowledge. By declining to help them, the medical researcher is acting within his moral rights; and a legal system cannot be faulted for recognizing and protecting these rights.

Suppose next that Nozick's medical researcher is willing to share with others-at a price. Because he is the only one who knows how to make the medicine and because this medicine is highly useful, affluent people are willing to pay a high price. The medical researcher therefore charges a high price, reckoning that he will make more money by selling dear to a few than by selling more cheaply to many. Nozick affirms, once again, that the medical researcher is within his rights to act in this way. It is his medicine to keep or to sell as he pleases.

Committed to a human-rights perspective, one might disagree with Nozick that property rights trump even the right to life. One might say that, when lives are at stake, society may confiscate the researcher's medicine and even compel him to make more or to share his knowledge. I do not dispute that a convincing response along these lines can be constructed and that this response can be worked up into a formidable challenge to the libertarian defense of SQ. Here I formulate, however, a different and more broadly based response that, for the sake of the argument, accepts the libertarian endorsement of strong property rights that entitle 
the medical researcher to act as he does. I accept this not because I agree with it, but because I can make a more effective response to libertarians by showing them that even their own paradigmatic commitments do not support the current regime against the human rights critique.

The current global pharmaceutical patent regime (SQ) is different from Nozick's story in one respect that is very important within the libertarian frame of thought. In the real world, innovators assert not merely physical property rights in product tokens they create, but also so-called intellectual property rights in abstract product types as well. I will show that, far from supporting intellectual property rights, libertarian thinking is in fact inconsistent with them.

Consider a simple example. Once upon a time, a clever woman took a piece of her wood and shaped it into a wheel. She then attached this wheel to a large basket and, with this primitive wheelbarrow, greatly eased her agricultural labor. Seeing her invention at work, others were eager to have such wheelbarrows too. The inventor can make additional wheelbarrows for sale, of course. But she will find it hard to charge exorbitant prices, because people can just make their own wheelbarrows or pay someone other than the inventor to produce them. In contrast to Nozick's imagined medical researcher, the wheelbarrow inventor cannot commercialize her invention without spreading the knowledge of how to reproduce it. (And this, of course, is the actual situation with regard to medicines today: what one company develops and tests at great cost, another firm can cheaply re-engineer.)

Suppose the inventor of the wheelbarrow now has the bright idea to claim ownership not merely of any wheelbarrows she herself constructs, but of the very type wheelbarrow. She is setting forth this idea not as a proposal for the consideration of all, but rather asserts it as a natural right. Just as all persons have a natural, pre-institutional right not to be murdered (and perhaps to own the food they have grown), so all persons have a natural, pre-institutional right to "intellectual property" in their inventions-regardless of others' consent.

If there were such a natural right, independent of any and all human laws and conventions, then our inventor would have veto powers over the making and using of wheelbarrows by other persons anywhere; anyone intending to make or acquire a wheelbarrow would then be required to bargain with her for her authorization. The natural right would have analogous implications for medicines. And one might then say that the TRIPS Agreement has not given rise to new constraints on the production, sale, and use of medicines but has merely (partially) recognized natural constraints that existed all along and incorporated these constraints into the international legal framework. It would still be true, in a sense, that the adoption, implementation, and enforcement of this agreement has taken something away from generic manufacturers and also from the poor patients who were benefiting from the availability of generic medicines at competitive market prices. But what it took away would never have been, morally speaking, theirs to begin with. Even in the absence of patents, it was wrong for generic manufacturers to supply cheap drugs to poor patients without the innovator's authorization. What the TRIPS 
Agreement has taken away, then, is the opportunity to commit moral crimestheft, counterfeiting, piracy — crimes whose legal recognition and suppression has finally been extended to nearly all countries around the world.

But is there really such a natural right of inventors not to have their inventions copied without their authorization? Within a libertarian frame of thought, such a natural right is deeply puzzling. Before the invention, all were free to build wheelbarrows with their own hands, wood and reed, without anyone's permission. Yet as soon as someone actually does this, the freedom of the others supposedly disappears - displaced by the need to bargain with the inventor for her permission. Why should anyone, by doing something creative with her stuff, be able unilaterally to limit what all the rest of us can do with our stuff? Why should one person be able unilaterally to impose new constraints on your conduct and property?

The woman can answer that your erstwhile freedom to make wheelbarrows was not worth much in advance of her invention. And she can add that, even with the encumbrance she insists upon, her invention still makes you better off than you would otherwise be by giving you the new option of making a wheelbarrow after buying her authorization.

This answer has a certain plausibility-but not within a libertarian frame of thought. Libertarianism is focused on the values of freedom, property, and consent. It cannot permit someone to impose an exchange upon you, no matter how beneficial this exchange may be for you. So the innovator has no right, without your permission, to deprive you of a right even if she gives you something much more valuable in return. No matter how great a benefit she may have foisted upon you, she is not entitled to divest you, without your consent, of your freedom to make wheels and wheelbarrows with your own hands and materials. As Nozick forcefully insists, even the voluntary acceptance of large benefits that were conferred on the express understanding of reciprocation does not create any obligations to reciprocate. ${ }^{22}$

Libertarianism is the philosophical tradition most friendly to natural property rights, taking them to be absolute constraints on the design of social institutions. Even if lives could be saved by taxing every affluent citizen a dime a year, doing so would still be morally intolerable - or so Nozick asserted. This status of rights to freedom and property as absolute constraints is inconsistent with "intellectual" property rights which would permit people unilaterally to place new limits on the freedom of others and (in particular) on what they may do with their property. The fact that others have pioneered a new dance or dish or gadget or medicine gives them no right to restrict what you may legitimately do with your body and property. So long as you have violated no rights in learning about the invention and have not contracted otherwise, you are within your rights when you try to copy their dance (with a willing partner) or try to reproduce their dish, gadget, or medicine from materials you legitimately own. Others may try to keep their invention secret from you, of course, and share it only with those who promise not to share it farther. But if you, having made no such promise, chance upon the invention, you are free to try to reproduce it. 
The discussion of the libertarian challenge leads then to a surprising conclusion. Libertarian thought does not merely fail to vindicate intellectual property rights but actually condemns them. From a libertarian point of view, the enforcement of intellectual property rights is expropriation which, as others keep inventing things, increasingly limits what you may do with your property. Far from supporting a natural right to intellectual property that could override the freedom to reproduce the inventions of others, the libertarian tradition defeats such a right and vindicates the rights of generic producers and their customers. They may transact with one another on mutually acceptable terms provided only that they are not bound by any voluntary contract to refrain from such activity. Restricting their activities through the imposition of intellectual property rights violates their natural rights to do with their property as they wish.

I do not endorse libertarian thinking and the priority it gives to property rights. Rather, I think that human laws and conventions should be designed and reformed in light of a broader range of human needs and interests among which those recognized in the main human rights documents are of greatest weight. On this view, the question of intellectual property rights should be treated instrumentally. Intellectual property rights should be instituted and fine-tuned, maintained or abolished so as best to realize human rights (and other human needs and interests). I support intellectual property rights as embedded in SQ + HIF because I believe that they would serve important human ends better than any feasible alternative (including abolition of all intellectual property rights).

Some defenders of intellectual property rights share this instrumental view. With them we must examine the empirical facts in order to ascertain in what contexts such rights do more harm than good, in what contexts they can be helpful, and how they should best be specified and embedded in the contexts in which they are helpful. Other defenders of intellectual property rights insist that such rights are natural rights and therefore must be instituted everywhere regardless of consequences. This kind of thinking resembles and appeals to the libertarian tradition. But, on closer inspection, it can find no home there. Libertarianism indeed rejects the instrumental perspective. But it pre-empts the question of intellectual property rights in the opposite direction: the ordinary physical property rights that libertarians hold sacrosanct are inconsistent with any powers on the part of others unilaterally to place limits on how a person may use her own body and property. According to libertarianism properly understood, the thieves and pirates are not those who reproduce an invention without permission, but those who use state power to suppress owners' free use of their property in order to extort payments from such owners.

\subsection{Neglecting the Diseases of the Poor}

Very poor people cannot obtain basic necessities while rich people have vastly more than they need. Libertarians do not find this problematic as such. They 
would argue that affluent people are entitled to use what they own as they see fit, and that it would be wrong for the state, or anyone else, to compel them to give some of their assets to the poor.

A highly uneven distribution of income and wealth can influence the priorities of pharmaceutical research (note 11). If those interested in anti-hair loss products are disposed to pay much more than those in need of a medicine against Chagas disease, then profit-oriented pharmaceutical companies will target hair loss in preference to Chagas. In this way, diseases concentrated among the poor come to be systematically neglected.

Again, libertarians do not find this wrong in principle. And they do find it morally unacceptable to take money from the rich in order to support research into the diseases of the poor even when such research would lead to medicines that poor people need for their health and survival. Owners have rights in the full use and enjoyment of their property; they must not harm others, but they are not required to help them.

In responding to this challenge, I again accept, for the sake of the argument, these central libertarian commitments in order to formulate a response that may convince those who find themselves in sympathy with libertarian sentiments.

The present setting of research priorities would be supported by overridingly strong property rights if the existing distribution of these rights had a morally sound pedigree of the sort libertarian theorists envisage. But without such a pedigree, the existing huge economic inequalities in de facto ownership have little or no justificatory force. Imagine for a moment a human world whose economic distribution resembles ours, but whose inhabitants have just sprung into existence. In this fictional world, the more powerful impose on the rest an institutional order that reserves for themselves the vast majority of wealth, thereby leaving a nonconsenting three-quarters of humankind with insecure access to the most basic necessities. Libertarian thought does nothing to legitimate the economic advantages of the rich in this world. Their greater possessions are founded on mere assertion backed by power.

Are existing property rights in our world well founded? Consider today's highly unequal global economic distribution. ${ }^{23}$ Which factors determine who ends up where in this economic hierarchy? It turns out that citizenship and income class at birth determine about eighty percent of people's economic position, ${ }^{24}$ which is hardly surprising given that gross national incomes per capita vary between $\$ 110$ and $\$ 76,450 .{ }^{25}$ Libertarians would not find such great international differences disturbing if these had accumulated, say, through differential diligence and thrift compounding over generations. But the huge inequalities in our world did not accumulate in such a benign way. The social starting positions of the poor and of the affluent have emerged from a single historical process that was pervaded by massive, grievous wrongs. The present circumstances of the global poor are significantly shaped by a dramatic period of conquest and colonization, with severe oppression, enslavement, even genocide, through which the native institutions and cultures of four continents were destroyed or severely traumatized. The 
present circumstances of the affluent are shaped by the same historical process. Some of the countries that give their citizens a great head start today owe their very existence to genocide and ethnic cleansing. These undeniable historical facts undermine the libertarian thought that existing holdings have a moral standing that exempts them from claims based on human rights.

The historical crimes just mentioned play no role in the human rights argument I have formulated. Rather, they undermine one particular reply to this argument. The human rights argument is forward-looking. Whatever human history may have been like, we should now structure national and international rules-including those governing the development and distribution of new medicines - so that at least human rights (and perhaps important other human needs) are fulfilled insofar as this is reasonably possible. When rules are known to be associated with an enduring massive human rights deficit that is avoidable by modifying these rules, then it is unjust - a violation of human rights - to maintain the former. In particular, it would be a violation of human rights to insist on the perpetuation of SQ when the alternative of SQ + HIF is known to be available.

A libertarian reply to this argument is that such a human rights fulfilling regime requires resources and that these resources are simply not morally available. The needed resources are owned by people or nations who are entitled to refuse to contribute them to solving others' problems. Affluent countries are free to contribute to the HIF if they like, but they are equally free, morally, to retain what they own - even when their doing so will leave human rights massively unfulfilled.

My response to this reply is that, even if it is indeed always permissible to refuse to contribute to the fulfillment of human rights by sharing what one legitimately owns, the actual history of existing holdings does not confer upon them, according to libertarian principles, the moral standing that the reply requires. Given the actual history, affluent people and nations cannot have the kind of confidence in the full legitimacy of their holdings that would entitle them to decline to contribute a few hundredths of one percent of their income toward making our newly globalized pharmaceutical patent regime much more responsive to the health needs of poor people, whose starting positions make them victims of the same unjust past that gives the affluent such vastly superior starting positions.

\section{Conclusion}

The preceding three sections have refuted some popular objections to the human rights argument in some detail. I could go on refuting less prominent objections for many more pages - a great deal of human inventiveness is expended on rationalizing the advantages of the affluent. Leaving this task to others or to future work, I conclude by reiterating that the human rights argument is straightforward. Its central point is that we must not continue to uphold a pharmaceutical innovation regime that is known to be associated with a massive human rights 
deficit if this deficit is reasonably avoidable through a feasible modification of that regime. The essay has shown that creating the HIF is a feasible modification that would avoid (depending on the amount of its funding) at least a substantial portion of this human rights deficit. ${ }^{26}$ Continuing the status quo despite this available alternative violates the human rights of those whose access to vital medicines it jeopardizes.

\section{Notes}

${ }^{1}$ This essay has been adapted from chap. 6 of Aidan Hollis and Thomas Pogge, The Health Impact Fund: Making New Medicines Accessible to All (New Haven, CT: Incentives for Global Health, 2008), available at http://www.healthimpactfund.org. While I did write the initial draft of this chapter (in July 2008), the Health Impact Fund project is a joint effort to which many others have also contributed greatly. Aidan Hollis, especially, has been thoroughly involved in this effort and has played a key role in shaping the HIF proposal as well as the group developing it. I also want to acknowledge generous support for our work from the Australian Research Council, the BUPA Foundation, the European Commission, the Australian National University's Centre for Applied Philosophy and Public Ethics, and Oslo University's Centre for the Study of Mind in Nature.

${ }^{2}$ This Agreement on Trade-Related Aspects of Intellectual Property Rights was adopted in the mid1990s in connection with the foundation of the World Trade Organization (WTO). The WTO website provides more information: http://www.wto.org/english/tratop_E/trips_e/trips_e.htm. For a more critical perspective, see also Oxfam, Investing for Life, Oxfam Briefing Paper, November 2007, p. 20, available at http://www.oxfam.org/en/policy/bp109_investing_for_life_0711.

${ }^{3}$ This classification is introduced in World Health Organization, Macroeconomics and Health: Investing in Health for Economic Development ("Report of the Commission on Macroeconomics and Health") (Geneva: WHO, 2001), 88-89, available at http://whqlibdoc.who.int/publications/2001/ 924154550x.pdf. Type I diseases are "global" diseases, which have a substantial presence in both rich and poor countries. Type II diseases are ones that are much more common in poor than in rich countries.

4"When India signed the World Trade Organization's agreement on intellectual property in 1994, it was required to institute patents on products by January 1, 2005. These rules have little to do with free trade and more to do with the lobbying power of the American and European pharmaceutical industries. India's government has issued rules that will effectively end the copycat industry for newer drugs. For the world's poor, this will be a double hit—cutting off the supply of affordable medicines and removing the generic competition that drives down the cost of brand-name drugs." Editorial, "India's Choice," New York Times, January 18, 2005.

${ }^{5}$ See especially Article 31 of the TRIPS Agreement (cited in note 2 above) and also World Trade Organization, "Declaration on the TRIPS Agreement and Public Health," Doha WTO Ministerial, available at http://www.wto.org/English/thewto_e/minist_e/min01_e/mindecl_trips_e.htm.

${ }^{6} \mathrm{We}$ are currently working on a study about the potential role of cell phone technology in distributing and monitoring the distribution of HIF-registered products. This technology is amazingly cheap and widely used even in the poorest countries. Patients could use their phone to pay for medicines and then also use this phone to report excessive prices or to answer questions about their experience with the product. Such random interviews could provide evidence about how much of a specific medicine was actually consumed in some specific geographical area and what health gains per unit were thereby achieved.

${ }^{7}$ See Hollis and Pogge, The Health Impact Fund, 19-20.

${ }^{8}$ This would be so because most markets today display only a very imperfect competition among generic producers, because large sales volumes of HIF-registered medicines would lower production costs per unit, and because HIF-registrants would often benefit from selling even below cost. 
${ }^{9}$ On how to define the lowest feasible cost, see Aidan Hollis, "The Health Impact Fund and Price Determination," IGH Discussion Paper no. 1 (2009), available at http://www.yale.edu/macmillan/ igh/files/papers/DP1_Hollis.pdf.

${ }^{10}$ They will want to do this so long as the marginal financial gain, arising mainly from the HIF reward for the additional health impact facilitated by the lower price, exceeds the marginal loss from the price reduction, that is, (expressed in a differential inequality) so long as

$$
\delta \mathrm{Q}(\mathrm{R}+\mathrm{p}-\mathrm{c})>\mathrm{Q} \delta \mathrm{p} .
$$

Here $\mathrm{Q}$ stands for the consumed quantity of the medicine, $\mathrm{R}$ for the average HIF reward per unit sold, $\mathrm{p}$ for the sales price per unit, and $\mathrm{c}$ for the marginal cost per unit. The HIF will probably impose not merely an upper, but also a lower price limit in order to deter frivolous use and waste (which might result in environmental damage). If the condition stated in the inequality holds all the way down to this lower limit, then the registrant will earn most by choosing this lowest permissible price for its product.

${ }^{11}$ See Sean Flynn, Aidan Hollis, and Mike Palmedo, "An Economic Justification for Open Access to Essential Medicine Patents in Developing Countries," Journal of Law, Medicine \& Ethics 37 (June 2009), 184-208.

${ }^{12}$ See in this context the proof in the Technical Appendix of Hollis and Pogge, The Health Impact Fund, 94-95. This proof assumes that the HIF's reward rate (in dollars per QALY) will be the same for all registered products in a given year and that the reward rate will not be very heavily dependent on only one product. The proof also assumes that innovators correctly decide in a profit-maximizing way which products they will register with the HIF and which ones not. The proof then shows that each HIF-registered product gains QALYs at lower cost per QALY than each product that is not HIF-registered. The underlying intuition is straightforward. What a company earns on a medicine can always be understood as the medicine's global QALY impact multiplied by its average earnings per QALY. (This is so regardless of whether the medicine is HIF-registered or not.) Any medicine will evidently gains QALY impact if it is registered (and therefore sold at a low price and marketed for health impact) than if it is not registered (and therefore sold at a high price and marketed for sales). Therefore, a company's correct decision not to register one of its medicines reflects the fact that it will thereby earn from this medicine substantially more money per QALY than the HIF reward rate. That such a company earns more per QALY means that the public pays more per QALY for such non-registered medicines (variable cost plus mark-up) than it pays for registered medicines (variable cost plus HIF reward).

${ }^{13}$ Hollis and Pogge, The Health Impact Fund, chap. 9, provides an overview of such other alternatives to $\mathrm{SQ}$.

${ }^{14}$ This idea goes back to Henry Shue, Basic Rights (Princeton, NJ: Princeton University Press, 1980). It was refined in Philip Alston and Katarina Tomaševski, eds., The Right to Food (Dordrecht: Martinus Nijhoff Publishers, 1984) and in Asbjørn Eide, Wenche Barth Eide, Susantha Goonatilake, and Joan Gussow, eds., Food as a Human Right (Tokyo: United Nations University Press, 1984), esp. 169-74. This account then found its way into Article 15 of General Comment 12 (http://www.unhchr.ch/tbs/doc.nsf/0/3d02758c707031d58025677f003b73b9?Opendocument), adopted by the UN Committee on Economic, Social and Cultural Rights in 1999, which reads as follows: "The right to adequate food, like any other human right, imposes three types or levels of obligations on States parties: the obligations to respect, to protect and to fulfill. In turn, the obligation to fulfill incorporates both an obligation to facilitate and an obligation to provide. The obligation to respect existing access to adequate food requires States parties not to take any measures that result in preventing such access. The obligation to protect requires measures by the State to ensure that enterprises or individuals do not deprive individuals of their access to adequate food. The obligation to fulfill (facilitate) means the State must pro-actively engage in activities intended to strengthen people's access to and utilization of resources and means to ensure their livelihood, including food security. Finally, whenever an individual or group is unable, for reasons beyond their control, to enjoy the right to adequate food by the means at their disposal, States have 
the obligation to fulfill (provide) that right directly. This obligation also applies for persons who are victims of natural or other disasters."

${ }^{15}$ Universal Declaration of Human Rights, article 25(1).

${ }^{16}$ See for instance Joanne Bauer and Daniel Bell, eds., The East Asian Challenge to Human Rights (Cambridge: Cambridge University Press, 1999).

${ }^{17}$ Universal Declaration of Human Rights, article 28.

${ }^{18}$ UNICEF is the United Nations Children's Fund. PEPFAR is US President's Emergency Plan for AIDS Relief. GAVI is the Global Alliance for Vaccines and Immunisation. GFATM is the Global Fund to Fight AIDS, Tuberculosis and Malaria.

${ }^{19}$ Editorial, "White Man's Shame," Economist, September 25, 1999, 89.

${ }^{20}$ See Thomas Pogge, Realizing Rawls (Ithaca, NY: Cornell University Press, 1989), 49-50.

${ }^{21}$ Robert Nozick, Anarchy, State, and Utopia (New York: Basic Books, 1974), 181.

${ }^{22}$ Nozick endorses this central commitment of libertarian thought, for example, in the context of his critique of H. L. A. Hart's principle of fair play: "Suppose some of the people in your neighborhood (there are 364 other adults) have found a public address system and decide to institute a system of public entertainment. They post a list of names, one for each day, yours among them. On his assigned day (one can easily switch days) a person is to run the public address system, play records over it, give news bulletins, tell amusing stories he has heard, and so on. After 138 days on which each person has done his part, your day arrives" (Nozick, Anarchy, State, and Utopia, 93). Nozick concludes about this case that, however much you may have enjoyed the efforts of the others, you are under no obligation whatever to staff the public address system.

${ }^{23}$ To illustrate. At currency exchange rates, the poorest half of world population, 3400 million, have less than three percent of global household income (data supplied by Branko Milanovic of the World Bank); the most affluent 30,000 (0.01 percent) people in the United States have two percent (based on Emmanuel Saez and Thomas Piketty, "Income Inequality in the United States, 19131998," Quarterly Journal of Economics 118 (2003): 1-39, as updated in "Tables and Figures Updated to 2007 in Excel Format," August 2009, available at elsa.berkeley.edu/ saez/). At currency exchange rates, the poorest half of the world's population, some 3400 million, had in the year 2000 about one percent of global private wealth (from James B. Davies, Susanna Sandstrom, Anthony Shorrocks, and Edward N. Wolff, "The World Distribution of Household Wealth," Table 10A, UNU-WIDER, December 5, 2006, available at http://www.iariw.org/papers/2006/ davies.pdf); in 2007, the world's 1125 billionaires had about three percent of global private wealth (Luisa Kroll, "World's Billionaires," Forbes, May 3, 2008, available at http://www.forbes.com/ 2008/03/05/richest-billionaires-people-billionaires08-cx_lk_0305intro.html).

${ }^{24}$ Branko Milanovic, "Global Inequality of Opportunity,” Development Research Group, World Bank, available at http://siteresources.worldbank.org/INTDECINEQ/Resources/Where6.pdf.

${ }^{25}$ World Bank, World Development Report 2009 (Washington, DC: World Bank, 2008), 352-53, 360; available at http://go.worldbank.org/O4MD5RGAF0. The extremes are occupied by Burundi and Norway, respectively. The average across all low-income countries is given as $\$ 578$ versus $\$ 37,566$ across all high-income countries (ibid., 353).

${ }^{26}$ See also Hollis and Pogge, The Health Impact Fund, chaps. 7-9. 